\title{
Bonus Systems as Tools for 'Managing' Managers - the Behavioural Effects of Performance-Based Financial Rewards
}

\author{
Isabelle Keßels ${ }^{1}$
}

Received: 11 August 2020 / Accepted: 26 November 2020 / Published online: 29 January 2021

(C) The Author(s) 2021

\begin{abstract}
In traditional reward systems, managers' key performance indicators must surpass an agreed target in order to achieve a financial bonus. This system is designed to motivate high performance; yet adverse behavioural effects are often observed. These include middle managers becoming incentivised to game the reward system and target negotiation process they are subject to. This paper discusses three approaches to preventing such undesirable behavioural effects: Firstly, a linear pay-for-performance system without a target floor for receiving a performance bonus. Secondly, a bonus banking system where managers participate at the company's losses as well as its gains. Thirdly, a proposal that uses the Beyond Budgeting approach which radically negates the core premises of the traditional reward system and replaces rewards for individual manager performance with those for wider team performance. These three approaches are compared and evaluated with respect to their potential to prevent unwanted manager behaviour, and on consideration of how effectively they may be operationalised.
\end{abstract}

Keywords Reward systems $\cdot$ Reward strategy $\cdot$ Bonus banking $\cdot$ Beyond budgeting

\section{Introduction}

Many companies still employ traditional budgeting, i.e. annual budgets as devices for planning and controlling the business's performance. These budgets determine targets for future performance, and allocate resources to reach these targets. Under this system, middle managers are typically evaluated and financially rewarded based on whether they meet targets set for their business unit. Consequently, as Fraser and Hope (2003a, 2003b) point out, budgets not only serve as technical devices for planning and controlling, they also "determine how

Isabelle Keßels

Isabelle.kessels@hhu.de

1 Department of Philosophy, Heinrich-Heine-University Duesseldorf, Universitätsstraße 1, 40225 Düsseldorf, Germany 
people behave in any given situation" (2003a, p. xviii). This paper brings into focus one way in which traditional budgeting influences managers' behaviour: the effects that using fixed individual targets to measure, evaluate, and reward managers has on their behaviour.

I start with a brief description of the typical reward system employed in traditional budgeting. Common problematic behavioural patterns that result from employing this reward system are indicated.

Then I discuss three approaches to avoid these behavioural effects:

(i.) The linear pay-for-performance approach

(ii.) The bonus banking approach

(iii.) The Beyond Budgeting approach

The first two are comparatively conservative solutions which are compatible with maintaining most technical aspects of traditional budgeting, merely reforming its reward system. The third is a more radical solution. The final section is dedicated to undertaking a comparative valuation and discussion of the merits and drawbacks of these three approaches.

\section{The Traditional Reward System and its Negative Behavioural Effects}

The annual budget, in traditional budgeting, allocates resources for business units and sets fixed individual targets ${ }^{1}$ for managers functioning as heads of these units (usually middle management). Accordingly, this budget can be used as an evaluation tool: allowing one to compare a business unit's actual performance against the target set for it; the business unit's performance, in turn, reflects how well the responsible manager performed. It is therefore not surprising that budgets affect how managers act and, ideally, should motivate them to reach their targets.

In what follows, I restrict the scope of my investigation by accepting three presuppositions about traditional budgeting: Firstly, I assume that middle management is involved in the formulation of annual budgets, at least to a certain extent. ${ }^{2}$ Secondly, for simplicity, I presume that bonuses are issued in the form of cash. ${ }^{3}$ Thirdly, I follow Jensen's (2001, 2003) assumptions about how a 'typical executive compensation plan' is structured: that is, how managers' performance is linked to financial rewards (pay-for-performance) in companies applying traditional budgeting (2001, p. 97). Jensen presents the following graphic:

\footnotetext{
${ }^{1}$ Depending on the business unit, targets can take the form of varying key performance indicators.

${ }^{2}$ The formulations of budgets are divided between the top-down, bottom-up and negotiated budget approaches in the first, senior management dictates the budget, while middle and lower management contribute more significantly to the formulation in the second, and the third represents a mixed form of the former two (Raghunandan et al. 2012, p. 112). Even in top-down budget formulation, where executive management has the sole authority, they still can be assumed to be in exchange with middle and lower management in order to effectively forecast. By delivering planning assumptions middle management thus influences the budget, even if it has no direct right to co-determine it.

${ }^{3}$ In reality, bonuses also are issued in other forms, for example, as company shares. As Becker and Christie (2009) indicate, issuing part of the annual bonus in the form of restricted company stock "ties the final value of the bonus to the share price "(p. 65) and thereby sets a different precondition that possibly gets rid of some the adverse behavioural patterns. A more extensive analysis will be needed to investigate this.
} 


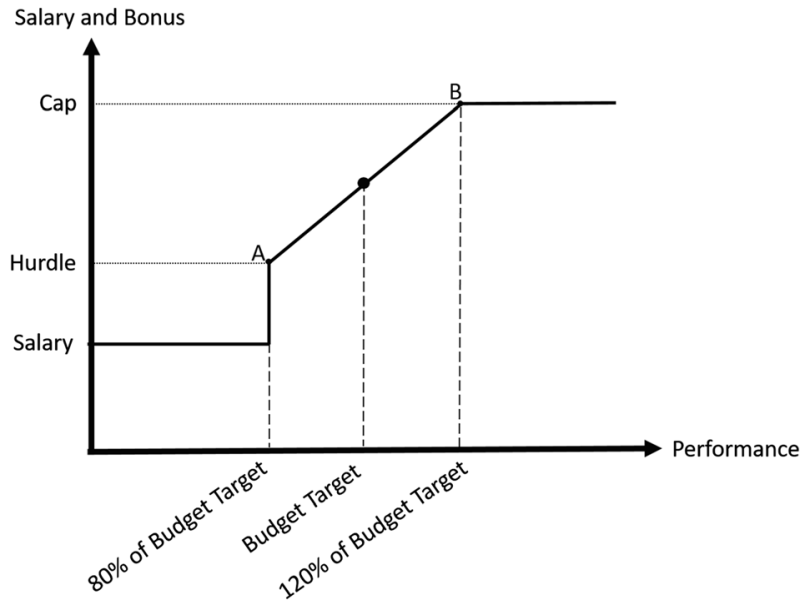

Fig. 1 Traditional reward system (Graphic based on Jensen 2001, p. 97.)

In this reward system, middle managers earn a fixed salary, but may gain additional bonuses. If the performance of their business unit reaches a certain hurdle (Jensen suggests $80 \%$ of the set target, illustrated as 'A' in Fig. 1) a bonus will be paid; the value of bonuses can be successively increased by increasing performance, until a cap is met (Jensen suggests $120 \%$ of the set target, illustrated as 'B') (Jensen 2001, p. 97). Depending on how well the business unit performs, the manager receives a bonus between the amounts indicated as 'A' and ' $B$ '. I will refer to this as 'the traditional reward system', and I take it to be associated with traditional budgeting as it relies on the setting of annual fixed targets for individual managers.

Implementing such a compensation system, which offers the chance of financial bonuses, is designed to serve as an extrinsic motivator for middle management: if they succeed, they will be rewarded; if they fail, they will miss out on this opportunity. ${ }^{4}$ If I described the setting of individual targets as a motivational tool above, the pay-for-performance system thus seems to be intended as a further amplifier of positive behavioural effects. But even though potential bonuses based on reaching fixed individual targets are meant as a source of motivation to perform well, there are observable adverse effects.

\section{Managers Game the Reward System}

One such behavioural pattern is managers manipulating their key performance indicators to maximise their bonuses. Jensen (2003) points out some ways in which the key performance indicator 'profit' can be significantly influenced - positively and negatively - by tampering with the accounting system:

"[...] by moving expenses from this year to the future (by delaying purchases, for example) or by moving revenues from future years into this year by booking orders early

\footnotetext{
${ }^{4}$ A further motivational factor will be that evaluations of how well a manager performs relative to her targets can be assumed to influence her chances of getting promoted - however, this is an aspect falling out of the scope of this paper.
} 
(as we described above by announcing future price increases, or by giving special discounts this year, or guaranteeing to repurchase goods in the future, and so on)." (Jensen 2003, p. 387)

Managers have an incentive to artificially increase their performance figures if their actual performance is slightly below the bonus hurdle; a strategy which remains attractive until the $120 \%$-cap is hit (Jensen 2003, p. 387). If, on the other hand, the actual performance is far below the 80\%-hurdle, "moving future expenses to the present and current revenues to the future" is incentivised as this "will increase the likelihood of a bonus in future years and increase the bonus amount at that time if they are in the payoff range" (2003, p. 387). The same strategy will also be employed if the actual performance could easily surpass the $120 \%$-cap: as overachieving will not increase this years' bonus, there is an incentive to keep their performance artificially near the $120 \%$ level and set favourable conditions for the following year (2003, p. 388). All these behavioural patterns are far from desirable for the organisation, as they distort relevant information and potentially destroy value (2003, p. 379).

\section{Managers Game the Target Negotiation}

Another adverse effect associated with traditional budgeting is managers 'gaming' the target (and budget) negotiation process. Negotiating targets that are easy to reach sets favourable conditions for achieving maximal bonuses. Furthermore, there is the additional benefit of setting relaxed targets which allow for managers "maintaining a margin of freedom and peace" within the firm (Radu 2011, p. 256). How easy it is to game the target negotiation process will depend on the amount of influence middle management has on the formulation of budgets. It could, for example, be done by suggesting planning premises that are more pessimistic than actually anticipated; manipulating the figures of the current year to make a loss seem even more severe than it is (as indicated in 2.1). This can result, as Hope and Fraser (2003a) wittily put it, in "a target that is inwardly comfortable to you, yet appears outwardly difficult to your superior" (p. 13).

Another way managers may manipulate budget and target negotiations is by asking for more resources than they actually believe are sufficient. Firstly, a surplus of resources makes it easier to reach an agreed target. Secondly, managers expect to have their budgets cut-back within the negotiation process, so managers' overestimate their resource needs as a matter of course in these discussions - creating a structural risk of distorted information about inputs and outputs within each negotiation (Hope and Fraser 2003a, p. 13).

Finally, and based on similar reasoning:

"If at the end of the budget period the amount budgeted is not fully spent, there is a tendency to spend it on anything, to avoid reducing the budget for the next period at the amount actually spent so far." (Radu 2011, p. 259.)

Again, such behavioural patterns lead to the distortion of information and, as a consequence, an inefficient allocation of resources.

\section{Background Assumption about Human Nature}

Jensen (2001) goes as far so as to claim that these two negative behavioural effects are inherent to the traditional reward system, and cannot be avoided without the dismantling of that system 
(p. 96). In Jensen and Meckling (1994), a similar claim is made: "it is the organizational structure and incentives that are at the root of the problem" of managers engaging in value destroying behaviour; "[t]he solution would then be not to fire the manager, but to reform the organizational policies" (p. 17). Jensen \& Meckling base their claim on a particular model of human nature: "the Resourceful, Evaluative, Maximizing Model", short REMM (p. 5). The REMM claims that people "are smart, but unscrupulous maximisers"; susceptible to motivation through extrinsic rewards, and "ready to use every loophole available to their own advantage, and trade everything in order to maximise their own satisfaction" (Petersen 2010, p. 30). Such a view of human nature serves both as a motivator for the initial implementation of the traditional reward system as a motivational tool, and as an explanation of why middle managers game this system: presumably, it's part of their nature. The fundamental distinction between accounts which recognise the problems which Jensen identifies with traditional reward systems is the extent to which they agree with this ontological assumption: whether they believe that these negative behaviours can be targeted in conjunction with the conclusions of such a view - which both underlines and undermines the traditional approach -, or if they require the re-organisation of the entire bonus system in line with a separate conception of human nature.

\section{Two Conservative, and One Radical, Approach to this Problem}

Clearly, the aforementioned behavioural patterns amount to negative effects of traditional budgeting: leading to the withholding and distortion of information, and to the destruction of value for the organisation (Jensen 2003, p. 379). Moreover, they illustrate a tension between middle managers' personal goals and those of the organisation. Three attempts to circumvent these adverse behavioural effects have been articulated by management scholars: two of which can be classified as comparatively conservative, compatible in large part with the traditional budgeting system. They merely suggest changes to the traditional reward system associated with, but not essential to traditional budgeting. The third represents a more radical approach.

\section{The Linear Pay-for-Performance Approach}

The main proponent of this approach is Jensen (2001, 2003), arguing for the need "to remove all the kinks from the pay-for-performance line - to adopt a purely linear bonus schedule" (2001, p. 98). As fig. 2 illustrates, in such a reward system the target initially set for the manager - whether it is 'target 1 ' or 'target 2' - would not influence the bonus she is paid (2001, p. 98).

Implementing a linear pay-for-performance system is compatible with formulating annual budgets that determine individual fixed targets - i.e., traditional budgeting -, it merely takes the kinks out of the established reward system. Comparing the actual performance to the set targets still serves as an evaluation tool under this system.

As this approach is put forward by Jensen himself, it seems fair to assume that his REMM account of human nature is a background assumption of his suggestion. The approach treats the negative behavioural effects as an isolated phenomenon which can be overcome without cultural changes within the firm. The strategy seems, rather, to be to change the organisation's processes (in this case: the reward process) so that they "tap and direct the creative energy of REMMs in ways that increase the effective use of our scarce resources" (Jensen and Meckling 1994, p. 19). 


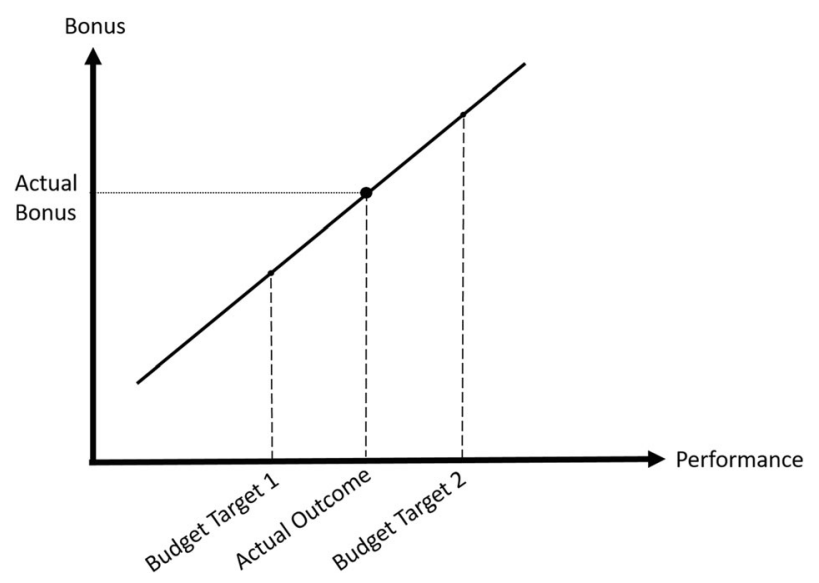

Fig. 2 Linear pay-for-performance system (Graphic based on Jensen 2001, p. 98)

\section{The Bonus Banking Approach}

The concept of bonus banking is discussed as a possible option by Becker and Christie (2009):

"Bonus banking is an incentive plan where part of the bonus earned in a year is "banked" in a bonus account, to be paid out in subsequent years. It differs from recent practice by allowing for the declaration of a negative bonus (sometimes called a "malus") where the amount in the bonus bank is reduced if subsequent corporate or individual performance declines, or if the initial assessment of performance upon which the bonus was based turns out to be wrong." (Becker and Christie 2009, p. 64.)

Figure 3 is a graph stemming from a briefing by consultancy firm Stern Steward \& Co, illustrating how they would implement this system.

Note that the dotted 'calculated bonus' line is straight and resembles the linear pay-forperformance system, meaning that bonuses rise continuously with increased performance. Unlike the previous model, from the point where target performance is met only one part of the additional bonus is paid out at the end of the year (as indicated by the kink in the 'paid out bonus' line); with the rest transferred to the 'bonus bank'. Even though there are kinks in this reward system, the negative behavioural patterns described above are avoided. Firstly, artificially under-performing to set favourable conditions for the next year could lead to a decrease in the balance on the bonus bank, and is thus not attractive to managers. Secondly, overperforming is continuously rewarded, both directly and in the near future; dis-incentivising managers keeping their performance at an artificial 'cap'. Thirdly, producing better numbers this year by moving its costs to the next - thereby setting unfavourable conditions for next year - is dis-incentivised as it may result in a negative bonus in the next year reducing the balance in the bonus bank.

The bonus banking system is, in principle, compatible with traditional budgeting and the formulation of individual targets as part of the annual budgeting process. However, the recommendations of actual bonus banking advocates, like the consultancy firm Stern Stewart 


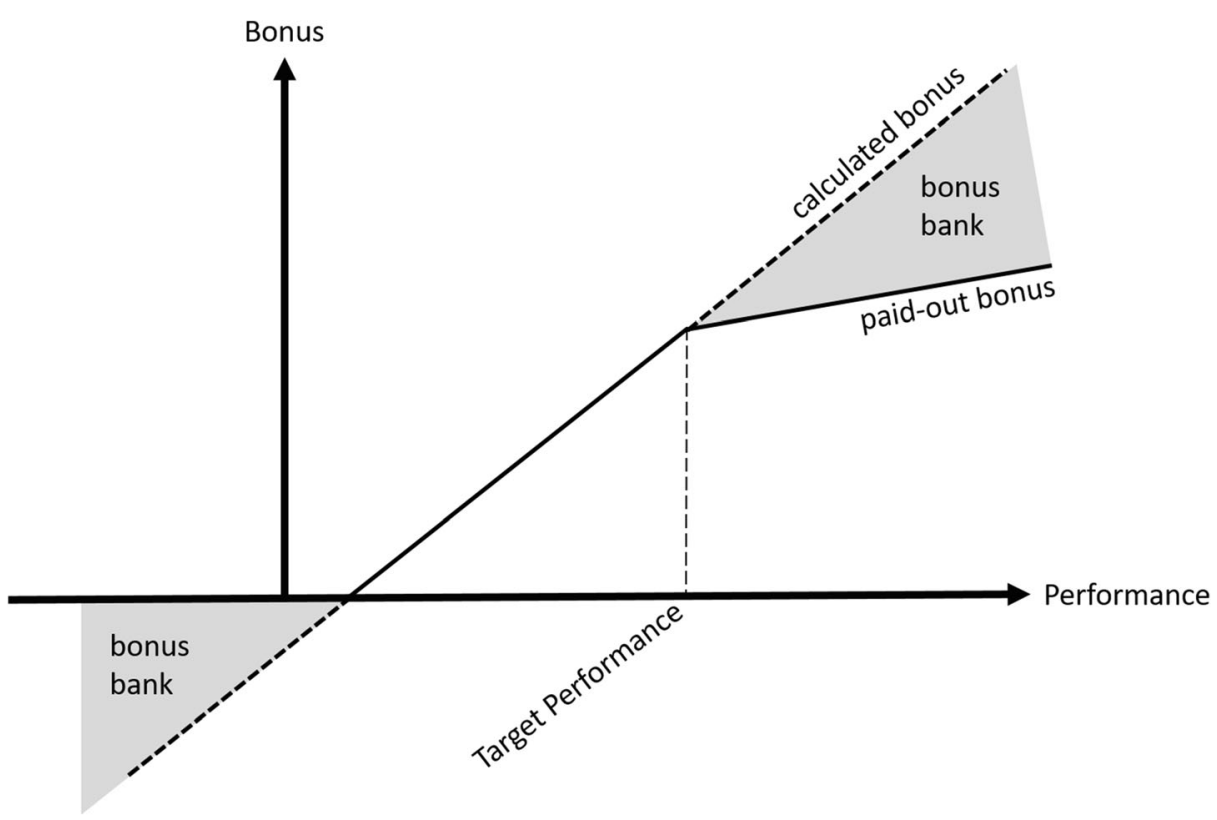

Fig. 3 Bonus bank system (Graphic based on Bischof et al. n.d., p. 7.)

and $\mathrm{Co}$, make it clear that integrating this bonus system into traditional budgeting models is not encouraged:

"Targets for compensation systems need to be derived from the long-term strategy and should not be renegotiated annually. [...] The annual planning process should therefore be independent of the target-setting process." (Bischof et al. n.d., p. 6.)

Bonus banks are associated by their supporters with an alternative way of evaluating managers' performance: instead of the annual targets, long term strategic targets should be set. Nonetheless, it is suggested that annual budgeting is preserved as a planning tool-evaluative functions, however, should be clearly separated from this.

In terms of background assumptions about human nature, the bonus banking approach is theoretically compatible with the assumption of the REMM; similar to Jensen's (2001, 2003) approach, bonus banking assume that "[t]he solution lies $[\ldots]$ in the structure of bonus payouts" (Bischof et al. n.d., p. 6). Yet, Stern Stewart and Co's recommendations encourage companies to strive for cultural changes along with procedural ones; e.g. "to extend the compensation scheme" to non-managerial employees, as the resulting increase in "transparency and consistency contributes to alignment of purpose and trust between management and other employees, which enables better relationships and better communication" (Bischof et al. n.d., p. 9). Such a change would not be required if the sole purpose of this re-structuring were to prevent that the self-interested, value maximising middle managers predicted by the REMM game the system. It implies that building a culture of trust, in which it is not automatically assumed that people will only act in their own interest, is part of overcoming the negative behavioural patterns identified. The problem is not treated as an isolated phenomenon, but as an aspect of organisational behaviour more widely. 


\section{Giving up Fixed Targets: The beyond Budgeting Approach}

A more radical approach to circumventing the described behavioural effects is to give up on traditional budgeting altogether and movie to a Beyond Budgeting system. The founders and main proponents of Beyond Budgeting are Hope and Fraser (2003a, 2003b). ${ }^{5}$ Their full account of developing an alternative management and controlling system, based on twelve principles, ${ }^{6}$ is too extensive to be adequately discussed here. Yet, their main proposals in regard to target setting and performance evaluation for middle management come through in the following sub-principles ${ }^{7}$ :

"Do not base rewards on a fixed performance contract. [...] consistently beat the competition rather than some negotiated number." (Hope and Fraser 2003b, p. 110)

"Evaluate and reward performance relative to peers, benchmarks, and prior periods. [...] base performance evaluation on some agreed formula tied to a range of relative targets." (Hope and Fraser 2003b, p. 110)

"Do not use rewards to "motivate people." [...] there is an important difference between providing attractive incentives that are designed to motivate people and providing some extra financial reward for team or group performance." (Hope and Fraser 2003b, p. 112.)

\footnotetext{
${ }^{5}$ Beyond Budgeting amounts to a significant trend of its own, both in theory and in practice. Next to their scientific publications, the late Hope \& Fraser established The Beyond Budgeting Round Table in 1998, a "membership organisation [...] founded on the Beyond Budgeting principles" (Beyond Budgeting Round Table n.d.-a). The Roundtable "helps organizations implement global best practices in planning and control; disseminates front - line implementation experience and identifies the keys to success; continuously improves adaptive planning and control to increase profit" (Réka et al. 2014, p. 577).

${ }^{6}$ The 12 principles, as stated by the Beyond Budgeting Round Table (n.d.-b), are grouped into leadership principles and management processes. The leadership principles are: "1. Purpose - Engage and inspire people around bold and noble causes; not around short-term financial targets 2. Values - Govern through shared values and sound judgement; not through detailed rules and regulations $\mathbf{3}$. Transparency - Make information open for self-regulation, innovation, learning and control; don't restrict it 4. Organisation - Cultivate a strong sense of belonging and organise around accountable teams; avoid hierarchical control and bureaucracy 5. Autonomy Trust people with freedom to act; don't punish everyone if someone should abuse it $\mathbf{6}$. Customers - Connect everyone's work with customer needs; avoid conflicts of interest" (ibid.) The guidance most relevant to the topic of bonus systems as tools for managing managers, here, are that less importance should be attached to short-term financial targets (1. Purpose), and that accountability should be attached to teams rather than individuals (4. Organisation).

The management processes are: "7. Rhythm - Organise management processes dynamically around business rhythms and events; not around the calendar year only $\mathbf{8}$. Targets - Set directional, ambitious and relative goals, avoid fixed and cascaded targets 9. Plans and forecasts - Make planning and forecasting lean and unbiased processes; not rigid and political exercises 10. Resource allocation - Forster a cost conscious mind-set and make resources available as needed; not through detailed annual budget allocations 11. Performance evaluation - Evaluate performance holistically and with peer feedback for learning and development; not based on measurement only and not for rewards only 12. Rewards - reward shared success against competition; not against fixed performance contracts" (ibid.) All six are relevant in the given context. Some are in tension with aspects and functions of traditional budgeting: its timing (7. Rhythm), its function as a forecasting instrument, which is used to determine fixed targets and resource allocation for the coming year (8. Targets, 9. Plans and forecasts, 10. Resource allocation). Others contradict the bonus system associated with traditional budgeting: namely that performance evaluation is done based on fixed targets, and that it is closely linked to rewards $(8$. Targets, 11. Performance evaluation, 12. Rewards).

${ }^{7}$ Note that this is still merely a selection of the sub-principles in regard to evaluating and rewarding as presented by Hope and Fraser (2003b). For the purpose of this paper, the chosen sub-principles are the most relevant.
} 
As these axioms highlight, Beyond Budgeting negates the core premises of the reward system under traditional budgeting: the setting of fixed targets, to individual managers and evaluation of performance relative to these targets.

Clearly this strategy circumvents the aforementioned behavioural patterns: however, the promised rewards of Beyond Budgeting are generally set higher, and aimed at achieving congruence between managers' (and employees') goals and the company's by promoting intrinsic motivation over extrinsic (e.g. financial) incentives (Hope and Fraser 2003b, p. 107). ${ }^{8}$ The "command, compliance, and control approach" to management is abandoned in favour of "mutual trust" (Hope and Fraser 2003a, p. 32). The whole approach is built on completely different background assumptions about human nature to those of the REMM: presuming "that people are motivated by their very nature, have the unconditional will to develop and grow" (Pfläging 2009, p. 21, translation IK). ${ }^{9}$

\section{Comparative Evaluation of the Three Approaches' Potential for Success}

An ideal solution should eliminate these negative behavioural effects, while being relatively easy to operationalize, i.e. impose as little change to other processes as possible. ${ }^{10}$ An evaluation of these approaches would, then, weigh off their effectiveness against their practicality. Out of the three approaches, Beyond Budgeting clearly imposes the most far reaching changes: if a more conservative approach appears sufficient to prevent the behavioural effects under discussion, most companies will perceive Beyond Budgeting as using a sledgehammer to flatten a nail. ${ }^{11}$ Therefore, I first discuss the likelihood of success using the conservative approaches.

Between the linear pay-for-performance and the bonus banking approach, the former appears the more restricted in the demands it makes of organisations. Both accounts are incommensurate with the traditional reward system, with only the linear pay-forperformance system compatible with annual individual fixed targets as a measure of performance. Bonus banking, at least in the operationalisation suggested by Stern Steward \& Co, dismisses set annual targets in favour of a clear distinction between the annual budget as a planning device, and the setting of long term strategic targets to evaluate individual performance. In my opinion the separation of planning and evaluation functions introduces a significant change, making the bonus banking approach closer in spirit and intention to alternative conceptions like Beyond Budgeting - which aims to change organisational thinking and get managers personally invested in the future of the company. Conversely, the linear payfor-performance approach is relatively close to traditional budgeting assumptions.

I am convinced that both the linear pay-for-performance and the bonus banking approach significantly weaken incentives to game the reward system. Here, I turn to the question of whether they prevent the gaming of target negotiation processes. For the linear pay-for-

\footnotetext{
${ }^{8}$ Evaluating, whether this goal can be realistically met would require a fuller investigation of both the technical and the behavioural aspects of Beyond Budgeting.

${ }^{9}$ This model of human nature, prevalent among proponents of Beyond Budgeting, is closely orientated at McGregor's (2006) 'Theory Y' (Hope and Fraser 2003b, p. 107; Pfläging 2009, p. 20ff).

${ }^{10}$ For the sake of simplicity, I presume no further problems which necessitate more extensive changes.

${ }^{11}$ There might be good reasons to switch to Beyond Budgeting, a full comparison between the pros and cons of it in comparison to traditional budgeting falls out of the scope of this paper, as it is focussed on problems associated with traditional budgeting's reward system.
} 
performance approach, I hold that success would depend on the determination of steepness of the pay-for-performance line. If the steepness is determined anew each year, then this system will not be able to reduce the tendency to negotiate ad hoc weak targets. Instead, it makes sense to maintain the steepness of the line across years; so that it is independent of annually negotiated targets. Under these conditions, the ability to negotiate weak targets will at least be limited.

The bonus bank system, as explicated by Stern Steward \& Co, suggests divorcing the determination of targets for managers (i.e. the target negotiation process) from the formulation of annual budgets as planning devices. How this would affect managers' honesty in presenting their forecasts of achievable performance and what resources they need calls for further empirical study; but it is plausible that the reliability of managers' forecasts could be improved if these do not translate immediately into targets. Nonetheless, under this system, managers still have an incentive to avoid budget cut-backs by whatever means available (asking for the maximum resources one can justify, and spending resources left over at the end of a year). Fully eliminating these adverse behavioural patterns by changing the reward system - to the linear pay-for-performance system or to the bonus banking system - seems an idle hope. This gets clearer when one considers the reward-independent incentive to negotiate relaxed targets: the comparative ease of the manager's time in work.

So what about the more radical approach? In eradicating fixed targets for individuals, Beyond Budgeting should theoretically succeed in eliminating the possibility of individual managers gaming the reward system. Performance evaluation based on Beyond Budgeting focuses on relative targets, comparing a team's performance with that of peers or competitors (Hope and Fraser 2003a, p. xix) - which managers cannot influence by unreliable forecasting. Accordingly, there is reduced opportunity, and ideally incentive, to try to negotiate relaxed targets. Resource allocation, subsequently, is not determined by a yearly budget; instead resources are made "available and accessible to frontline teams as and when required through fast-track approvals and easier access to operational resources" (2003a, p. 24). Hope \& Fraser further claim that "[t]his approach overcomes much of the game playing associated with resource allocation" (2003a, p. 24); if we accept this assessment, Beyond Budgeting also removes the second adverse behavioural effect of gaming target (and resource) negotiation. This approach, at least in theory, promises the highest potential of success.

Unlike the first two approaches, Beyond Budgeting is an holistic programme of extensive change that affects both technical and behavioural/sociocultural aspects of companies' operations and strategy; much of which is incompatible with traditional budgeting approaches. Since it requires not only alterations to a company's processes of budgeting, evaluating and rewarding, but to its whole organisational structure, changes in behaviour patterns resulting from transitioning from a traditional budgeting system to Beyond Budgeting may be manifold and unpredictable. Without further in-depth research, it is extremely difficult to evaluate both whether the theoretical premises of the Beyond Budgeting system are convincing and, secondly, to estimate whether it can successfully be implemented across firms and sectors, given the comprehensiveness of its demands and the variety or organisational priorities and cultures. On top of processual changes, Beyond Budgeting calls for changes to company culture and, with it, senior management's leadership culture: requiring the cultivation of a climate of mutual trust rather than control (Hope and Fraser 2003a, p. 32). As outlined above, this may require changes in company leaders' implicit assumptions about human nature. A successful implementation of Beyond Budgeting accordingly does not merely rely on middle 
management to accept changes to processes they are accustomed to (as with the other two approaches), but may also require senior management to change fundamental beliefs about how people are motivated, and how much control is required in leadership. Moreover, senior management is expected to relinquish a certain level of control, which may be met with resistance. Although it is likely that the implementation of one of the more conservative approaches would also be met with some level of reticence by managers, ${ }^{12}$ their responses may reasonably be expected to be more limited in the face of more modest reforms.

Hitherto, I have assessed the three approaches by weighing off effectiveness against practicability; emphasising that a viable solution must be easy to operationalise. Yet, we should also consider the sustainability of the changes achieved: Petersen (2010) claims that the REMM may amount to a self-fulfilling prophecy: "If we are seen as REMM men and treated like REMM men we might begin to act like REMM men." (p. 47.) ${ }^{13}$ This would imply that rewards systems developed with the background assumption that people generally aim to maximise their own benefit focus solely on eliminating the possibility that the system is gamed, and effectively provoke people to find new ways to game the system. If Petersen (2010) is correct, negative behavioural effects could only be overcome in a sustainable manner if the underlying perception of human nature is incorrect, or the nature it describes is malleable. Above, I indicated that, of the three approaches, only Beyond Budgeting is completely incompatible with the REMM. It might be concluded that Beyond Budgeting is the only approach promising sustainable success, yet this would be rash. The implementation of bonus banking, especially that suggested by Stern Stuart \& Co, already includes some limited changes to company culture, such as long-term goal-orientation amongst senior staff, and an extension of the reward-scheme to non-managers (Bischof et al. n.d., p. 6-9). Not only is the reward system changed, but also the evaluation process: it is thus possible to combine this approach with a change of the control exercised by top management, i.e. a shift of the company culture towards greater mutual trust and decentralised decision making. The bonus banking approach may be theoretically compatible with the presumption of the REMM of human nature, however, it appears to be more congruent with its rejection. ${ }^{14}$ If combined with additional measures (e.g. granting flexitime, the right to work from home, etc.) which manifest a shift in company culture, I believe that the bonus banking approach can represent a more sustainable solution. The linear pay-for-performance approach, on the other hand, is not associated with any real changes in company culture.

\footnotetext{
${ }_{12}$ Here are some foreseeable problems for the implementation of the two conservative approaches. In regard to the linear pay-for-performance system, Jensen (2003) writes: "Running a linear compensation system with no maximum limits means that up and down the hierarchy managers have to be willing to see some employees and/ or managers that report to them getting bonuses that are much larger than their own." (p. 401.) He suspects that "ego and jealousy" (p. 401) might lead to some resistant from top and higher management against this reward system. In regard to bonus-banking Becker and Christie (2009) write: "[B]onus-banking plans often have an unintentionally punitive tone. Bonuses can usually only be adjusted down, which can lead employees to feel that failure will be punished, but sustained success will go unrewarded." (p. 65.) They also add that "the market is often the final determinant of incentive compensation practices" (p. 65) and that companies might simply be unable to win suitably talented management personal for themselves with a bonus banking system, as long as the traditional reward system is still widely used.

${ }_{13}$ Pfläging (2009) makes a similar argument (p. 22).

${ }^{14}$ If the bonus banking approach were implemented as a mere procedural change and under the presumption that something akin to the REMM of human nature is correct, there is a real danger that middle management perceive it as an attempt to outsource financial risk to them, rather than an attempt at real participation. This should be avoided at all costs.
} 


\section{Conclusion}

Linear pay-for-performance and bonus banking approaches introduce reforms to traditional budgeting's reward system to reduce the negative behavioural pattern of middle managers gaming the reward system for the highest possible bonuses. Of these two approaches, bonus banking has the better chance of additionally effecting a pivot from reliance on yearly targets towards using long-term strategic goals as an evaluative principle; ameliorating the tendency of middle managers to give unrealistic planning premises to the yearly budget. The bonus banking approach is, on that basis, preferable. Beyond Budgeting promises even better results, but it is unclear how realistic achieving drastic changes to companies' organisational structure and culture would be, and at what cost it will come.

Based on these considerations, weighing the risk of resistance against the benefits of preventing value destroying behaviour, and achieving a higher goal congruence between managers and the company in the long run: I believe that bonus banking is the most promising approach. It is a sensible middle ground between the linear payfor-performance strategy, which is comparatively timid, and the Beyond Budgeting strategy, which can only sensibly be chosen when a company also faces significant problems resulting from technical aspects of the traditional budgeting system (a possibility bracketed in the present analysis). However, the culture of the company in question - that is, its level of change-adversity and the negative behavioural patterns shown, as well as its market for potential manager reappointment - will play a relevant role in individual decisions of implementing or not implementing any strategies discussed. ${ }^{15}$

Acknowledgments I thank Luke Beesley (University of Brighton) for comments on previous written versions of this article.

Funding Open Access funding enabled and organized by Projekt DEAL.

\section{Compliance with Ethical Standards}

Conflict of Interest The corresponding author states that there is no conflict of interest.

Open Access This article is licensed under a Creative Commons Attribution 4.0 International License, which permits use, sharing, adaptation, distribution and reproduction in any medium or format, as long as you give appropriate credit to the original author(s) and the source, provide a link to the Creative Commons licence, and indicate if changes were made. The images or other third party material in this article are included in the article's Creative Commons licence, unless indicated otherwise in a credit line to the material. If material is not included in the article's Creative Commons licence and your intended use is not permitted by statutory regulation or exceeds the permitted use, you will need to obtain permission directly from the copyright holder. To view a copy of this licence, visit http://creativecommons.org/licenses/by/4.0/.

\footnotetext{
${ }^{15}$ Recall that it is a premise of this paper that, for simplicity, I presumed that rewards are issued in the form of cash (cf. fn. 3). More change adverse companies might choose to experiment with issuing part of their rewards in form of restricted stock, and this might also effect a change in management's behaviour. This strategy fell out of the scope of this paper, but should be kept in mind as a further alternative.
} 


\section{References}

Becker, I., \& Christie, P. (2009). Bonus Banking: A Better Way to Reward? Directorship, April/May 2009,64 65.

Beyond Budgeting Round Table (n.d.-a). Beyond Budgeting Round Table and Membership. Retrieved October 10, 2019, from https://bbrt.org/what-is-the-beyond-budgeting-round-table-bbrt/.

Beyond Budgeting Round Table (n.d.-b). The 12 Beyond Budgeting Principles. Retrieved October 15, 2020, from https://bbrt.org/the-beyond-budgeting-principles/.

Bischof, B., Essex, S., \& Furtaw, P. (n.d.). Participating in Opportunities and Risks. Long Live the Bonus Bank!: The Re-Birth of an Old, but Strikingly Simple Idea. Retrieved October 11, 2019, from https://www. sternstewart.com/media/studie_40_participating_in_opportunities_and_risks_en_1.pdf.

Hope, J., \& Fraser, R. (2003a). Beyond Budgeting: How Managers Can Break Free from the Annual Performance Trap: Harvard Business School Publishing Corporation.

Hope, J., and R. Fraser. 2003b. New Ways of Setting Rewards: The Beyond Budgeting Model. Californina Management Review 45 (4): 104-119.

Jensen, M.C. 2001. Corporate Budgeting is Broken - Let's Fix it. Harvard Business Review, Reprint R0110F: 95-101.

Jensen, M.C. 2003. Paying People to Lie: The Truth about the Budgeting Process. European Financial Management 9 (3): 379-406.

Jensen, M.C., and W.H. Meckling. 1994. The Nature of Man. Journal of Applied Corporate Finance 7 (2): 4-19.

McGregor, D. 2006. The Human Side of Enterprise: Annotated Edition (Updated and with a new Commentary by Joel Cutcher-Gershenfeld). New York: McGraw-Hill.

Petersen, V.C. 2010. Self-Fulfilling Aspects of Unrealistic Assumptions in Management Theory. Philosophy of Management 9 (3): 27-48.

Pfläging, N. (2009). Die 12 neuen Gesetze der Führung: Der Kodex: Warum Management verzichtbar ist. Frankfurt / New York: Campus-Verlag. PII: B9780080454054006297.

Radu, M. 2011. The Budgetary Process - Reasons for Dissatisfaction. Annals of the University of Petroşani, Economics 11 (4): 255-262.

Raghunandan, M., N. Ramgulam, and K. Raghunandan-Mohammed. 2012. The Behavioural Aspects of Budgeting with particular emphasis on Public Sector/Service Budgets. International Journal of Business and Social Science 3 (14): 110-117.

Réka, C.I., P. Ştefan, and C.V. Daniel. 2014. Traditional Budgeting Versus Beyond Budgeting: A Literature Review. Annals of Faculty of Economics, University of Oradea, Faculty of Economics 1 (1): 573-581.

Publisher's Note Springer Nature remains neutral with regard to jurisdictional claims in published maps and institutional affiliations.

Isabelle Keßels is a research assistant in the department of philosophy at Heinrich-Heine-University Duesseldorf and conducts further postgraduate research at Duesseldorf Business School. Her work explores the relationships between knowledge claims, achievement, and success within philosophical and management discourses. 